\title{
Exploration on the Best Way of Separating Auricularia Auricula' Mother Strains
}

Xiaolong HE,

Shaanxi Engineering \& Technological Research

Center for Conversation \& Utilization of Regional

Biological Resources, College of Life Science,

Yanan University, Yanan 716000, China

Dianzhen WANG,

Shaanxi Engineering \& Technological Research

Center for Conversation \& Utilization of Regional

Biological Resources, College of Life Science,

Yanan University, Yanan 716000, China
Hui ZUO,

Shaanxi Engineering \& Technological Research

Center for Conversation \& Utilization of Regional

Biological Resources, College of Life Science, Yanan University, Yanan 716000, China

Xuhui ZHANG,

Shaanxi Engineering \& Technological Research Center for Conversation \& Utilization of Regional Biological Resources, College of Life Science, Yanan University, Yanan 716000, China

\section{Guimei REN \\ Shaanxi Engineering \& Technological Research Center for Conversation \& \\ Utilization of Regional Biological Resources, \\ College of Life Science, Yanan University, \\ Yanan 716000, China}

Abstract. 3 mother strains were obtained using 3 different separation methods (i.e. spore separation, sporocarp separation, and mushroominhabiting wood separation), respectively. These mother strains were processed to some extent. First, the mycelial growth rates of spore separation and sporocarp separation, were known to be fast, $0.39 \mathrm{~cm} / \mathrm{d}$ and $0.37 \mathrm{~cm} / \mathrm{d}$ respectively, but the rate of mushroominhabiting wood separation was the slowest, only $0.32 \mathrm{~cm} / \mathrm{d}$, after a statistical analysis. Second, the growth trend of the mycelium obtained using spore separation and sporocarp separation was good, but the mycelium obtained using spore separation was thicker, neater, and whiter, after a comparison. Third, an extracellular enzyme assay found that the enzymatic activity of the strains obtained using spore separation was the best. Finally, an high-temperature resistant test found that the strains obtained using spore separation and sporocarp separation were resistant to high temperature, and thus, it was concluded that spore separation was better than sporocarp separation and mushroominhabiting wood separation to separate the mother strains of auricularia auricula.

Keywords: Auricularia Auricula; Sporocarp Separation; Spore Separation; Tissue Separation; Mother Strains

\section{Introduction}

Auricularia auricular is also known as black fungus, chinesische morcheln, etc [1]. It belongs to auriculariales and is a type of famous edible fungi in China. It is an ideal health care product for the personnel in mining, chemistry, textile and other industries [2]. In recent years, the studies of the University of Minnesota show that auricularia auricular can reduce blood clots, relieve atherosclerosis, regulate human body's metabolism and treat diseases such as hypertension [3]. Therefore, a study of auricularia auricular is of important significance. As people's living standards are unceasingly improved, edible fungus as new green nutritional health care products are universally popular 
among the vast number of consumers. In the studies of auricularia auricular, cultivation process and polysaccharide extraction are mainly focused, but the separation of mother strains is reported rarely. In view of this actual situation, in this paper, the mother strains of auricularia auricular were separated using different samples, aiming to obtain high-quality auricularia auricular strains and lay a germplasm foundation for the high-yield cultivation of auricularia auricular.

\section{Materials and methods}

\subsection{Materials and equipment}

\subsubsection{Tested materials and reagents}

Auricularia auricular sporocarp, basswood, potato, cottonseed hull, bran, sawdust, rice, corn millet, millet, wheat, and carrots were chosen. Soluble starch solution, DNS (3,5-dinitrosalicylic acid), and distilled water were used as reagents [5].

\subsubsection{Equipment}

HV-110 vertical pressure steam sterilizer, AUW120D electronic balance, UOK-II-10 europtronic series ultrapure water machine, PYX-DHS-60X75-BS water-jacket thermostatic incubator, ZJS-1320 thermostatic bath oscillator, UV-2550 UV-vis spectrophotometer, HH-S4 electric-heated thermostatic water bath, clean bench, and common laboratory tools were applied.

\subsection{Experimental method}

\subsubsection{Separating mother strains}

\subsubsection{Separating materials}

$70 \%-80 \%$ ripe sporocarps with good appearance and no diseases were chosen and the impurities within them were removed. Basswood was prepared.

\subsubsection{The preparation of culture medium}

$200 \mathrm{~g}$ potato, $20 \mathrm{~g}$ glucose, $20 \mathrm{~g}$ agar, and $1000 \mathrm{ml}$ water were used. PDA culture medium was prepared using the conventional method [6].

\subsubsection{Separation methods}

(1) Spore separation

Materials to be separated were superficially disinfected with $75 \%$ alcohol and properly put into 5 sterile water contained beakers to wash, and then the moisture in these materials was sucked using sterile gauze. The rinsed agaric pieces were suspended in sterile PDA medium contained triangular flask using stainless steel hooks. The flask was put in a place exposed to sunshine at $24 \pm 1{ }^{\circ} \mathrm{C}$ after it was tightly covered with tampon [6].

(2) Sporocarp separation

Materials to be separated were superficially disinfected with $75 \%$ alcohol. Under sterile conditions, tissue blocks $\left(0.5 \mathrm{~cm}^{2}\right)$ were taken from the aseptic tissues of the edges of agaric pieces, and then inoculated on 10 PDA culture mediums and cultured under constant temperature $\left(22 \pm 1^{\circ} \mathrm{C}\right)$ and free from sunshine.

(3) Mushroominhabiting wood separation Mushroominhabiting wood with exuberant edible myceliums and no microbe infection and diseases was chosen and dried properly in wind. It was superficially disinfected with alcohol and the infectious microbe on its surface was burned to death using fire. Under sterile conditions, a piece of mushroominhabiting wood $\left(0.5 \mathrm{~cm}^{3}\right)$ was inoculated on 10 PDA culture mediums and cultured under constant temperature and free from sunshine to be a colony $(2-3 \mathrm{~cm})$.

\subsubsection{The purification of mother strains}

From the mother strains obtained using the above 3 separation methods, the tip myceliums were respectively chosen and purified when the colony grew to 2-3 cm, aiming to remove impurities and the strains of weak vitality.

\subsubsection{The rejuvenation of mother strains}

2.2.3.1 The ingredients and preparation of the medium for the rejuvenation

The ingredients of the medium are as shown in table 1. 
Table 1: The ingredients of the medium for purifying and rejuvenating mother strains

(Unit: g)

\begin{tabular}{|c|c|c|c|c|c|c|c|c|c|c|}
\hline No. & A & B & $\mathrm{C}$ & $\mathrm{D}$ & $\mathrm{E}$ & $\mathrm{F}$ & $\mathrm{G}$ & $\mathrm{H}$ & I & $\mathbf{J}$ \\
\hline $\begin{array}{l}\text { Natural } \\
\text { material }\end{array}$ & $\begin{array}{c}\text { Potato } \\
200\end{array}$ & $\begin{array}{c}\text { Cotton } \\
\text { seed hull } \\
200\end{array}$ & $\begin{array}{c}\text { Bran } \\
200\end{array}$ & $\begin{array}{r}\text { Sawdu } \\
\text { st } 200\end{array}$ & $\begin{array}{l}\text { Rice } \\
200\end{array}$ & $\begin{array}{c}\text { Broom } \\
\text { corn } \\
\text { millet } 200\end{array}$ & $\begin{array}{c}\text { Millet } \\
200\end{array}$ & $\begin{array}{l}\text { Wheat } \\
200\end{array}$ & $\begin{array}{c}\text { Peptone } \\
20\end{array}$ & $\begin{array}{c}\text { Potato } \\
20 \\
\text { carrot } 20\end{array}$ \\
\hline $\mathrm{KH}_{2} \mathrm{P}_{4}$ & 3 & 3 & 3 & 3 & 3 & 3 & 3 & 3 & 0 & 0 \\
\hline $\mathrm{MgSO}_{4}$ & 1.5 & 1.5 & 1.5 & 1.5 & 1.5 & 1.5 & 1.5 & 1.5 & 0 & 0 \\
\hline $\mathrm{VB}_{1}$ & 0.01 & 0.01 & 0.01 & 0.01 & 0.01 & 0.01 & 0.01 & 0.01 & 0 & 0 \\
\hline
\end{tabular}

Note: A-PDA synthetic medium; B-the synthetic medium prepared with fresh seeds boiling juice; $C$ - the synthetic medium prepared with fresh bran boiling juice; $D$ — the synthetic medium prepared with sawdust boiling juice; $E$ - the synthetic medium prepared with rice boiling juice; $F$ - the synthetic medium prepared with broom corn millet boiling juice; $G$ - the synthetic medium prepared with millet boiling juice; $H$-the synthetic medium prepared with wheat boiling juice; I-glucose peptone medium; J-potato and carrot medium. $1000 \mathrm{ml}$ water, $20 \mathrm{~g}$ glucose and $20 \mathrm{~g}$ agar were added into the ten mediums.

\subsubsection{Rejuvenating mother strains}

The tip myceliums of different tissues of mother strains were inoculated into ten mediums (A, B, $\mathrm{C}, \mathrm{D}, \mathrm{E}, \mathrm{F}, \mathrm{G}, \mathrm{H}, \mathrm{I}, \& \mathrm{~J})$ and cultured under constant temperature $\left(22 \pm 1{ }^{\circ} \mathrm{C}\right)$ and free from sunshine. Comprehensive nutrient contents were provided for these samples, to restore their good biological properties [13].

2.2.4 The observation test of the growth conditions of mother strains

PDA culture medium was prepared using a conventional method: $200 \mathrm{~g}$ potato, $20 \mathrm{~g}$ glucose, and $18-20 \mathrm{~g}$ agar; $1000 \mathrm{ml}$ water was added. The rejuvenated mother strains were cut into the same size $\left(0.5 \mathrm{~cm}^{2}\right)$ of blocks along the edge of the colony and inoculated on PDA culture medium; 12 materials were prepared for each separation method. The strains were cultured under constant temperature $\left(22 \pm 1{ }^{\circ} \mathrm{C}\right)$ and free from sunshine. Their growth was observed.

\subsubsection{Extracellular enzyme assay}

\subsubsection{The preparation of solution}

DNS reagent was prepared: $6.9 \mathrm{~g}$ crystallized phenol was dissolved in $15.2 \mathrm{ml} \mathrm{NaOH}$ solution $(10 \%)$. Then, the mixed solution was diluted using distilled water until $69 \mathrm{ml}$, and $6.9 \mathrm{~g}$ sodium bisulfite was added into it; $255 \mathrm{~g}$ sodium tartrate was weighed and added into $300 \mathrm{ml} \mathrm{NaOH}$ solution (10\%), and then added into $880 \mathrm{ml}$ 3,5-dinitrosalicylic acid (1\%). The solution was placed at room temperature for 7 days; $5 \%$ soluble starch solution was prepared; $5 \mathrm{~g}$ soluble starch was dissolved in $100 \mathrm{ml}$ ice acetic acid. 2.2.5.2 The preparation of crude enzyme Strains were inoculated into 5 bottles of liquid mediums respectively and kept statically for $24 \mathrm{~h}$, and cultured under constant temperature $\left(22^{\circ} \mathrm{C}\right)$ and oscillated at the rate of $220 \mathrm{r} / \mathrm{min}$. On the 7 th day, 3 bottles of strain liquid were randomly chosen to suck and filter, founding the filter liquor was crude enzyme.

\subsubsection{Amylase activity measurement}

$1.5 \mathrm{ml}$ soluble starch $(5 \%)$ and $0.5 \mathrm{ml}$ crude enzyme were added into enzyme solution tube, kept for $30 \mathrm{~min}$ at $38^{\circ} \mathrm{C}$. Then, $1.5 \mathrm{ml}$ DNS was added into the solution and boiled for $10 \mathrm{~min}$. Then, $2.5 \mathrm{ml}$ distilled water was added to measure OD value.

\subsubsection{High-temperature resistance measurement}

The rejuvenated mother strains were cut into the same size $\left(0.5 \mathrm{~cm}^{2}\right)$ of blocks along the edge of the colony and then inoculated on the slope of the above PDA synthetic medium (in which all parts grew good in the process of rejuvenation); 12 materials were prepared for each separation method; the strains were cultured under constant 
temperature $\left(22 \pm 1^{\circ} \mathrm{C}\right)$ and free from sunshine for 2 days. The mother strains cultured for 2 days were cultured again at $30^{\circ} \mathrm{C}$ constant temperature and free from sunshine for 1 day, and then cultured under constant temperature $\left(22 \pm 1{ }^{\circ} \mathrm{C}\right)$ and free from sunshine, in which the growth of these strains was observed until the slope was full of their mycelium and also compared with that of the mother strains cultured under constant temperature $\left(22 \pm 1^{\circ} \mathrm{C}\right)$.

\section{Results and analysis}

\subsection{Separation and purification result}

No pollution existed in the process of separation. The mother strains obtained using separation methods became pure after purification and infectious microbe removal.

\subsection{Rejuvenation result}

An analysis of the rejuvenated growth using 10 mediums found that the mycelium growth of the cultured 3 mother strains was the best on PDA synthetic medium.

\subsection{The result of the observations on the mycelium growth of the cultured 3 mother strains}

The strains obtained using spore separation, sporocarp separation, and mushroominhabiting wood separation were inoculated into PDA synthetic medium respectively to be cultured, and a statistical analysis of germination time and mycelium growth found that the growing rates of the 3 mother strains were different. A multiple comparison on the 3 mother strains is as shown in table 2.

Table 2: A multiple comparison on the mycelium growth and daily growing rate in the selected mediums

(Unit: $\mathrm{cm} / \mathrm{d}$ )

Note: $"++++$

\begin{tabular}{|c|c|c|c|c|c|c|}
\hline Separation method & $\begin{array}{c}\text { Germination } \\
\text { time }\end{array}$ & $\begin{array}{l}\text { Mycelium } \\
\text { growth }\end{array}$ & $\begin{array}{l}\text { Full-tube } \\
\text { time }\end{array}$ & $\begin{array}{l}\text { Growing } \\
\text { rate }\end{array}$ & $X-3$ & $X-2$ \\
\hline Spore separation & $1.5 \mathrm{~d}$ & +++++ & $14 d$ & 0.39 & $\begin{array}{c}0.07 * \\
*\end{array}$ & 0.02 \\
\hline Sporocarp separation & $1.5 \mathrm{~d}$ & ++++ & $15 d$ & 0.37 & $0.05^{*}$ & \\
\hline $\begin{array}{l}\text { Mushroominhabiting } \\
\text { wood senaration }\end{array}$ & $2 d$ & +++ & $17 \mathrm{~d}$ & 0.32 & & \\
\hline
\end{tabular}

The result in table 2 showed that the germination time was the shortest when spore separation and sporocarp separation were used and the mother strains were obtained only in 1.5 days on average, but 2 days were required when mushroominhabiting wood separation was applied; the mycelium growth was different. Therefore, it is known that the mycelium growth of the strains obtained is good using spore separation and sporocarp separation, but poor using mushroominhabiting wood separation.

\subsection{Extracellular enzyme assay results and analysis}

The strains, obtained using spore separation, sporocarp separation, and mushroominhabiting wood separation, were tested in terms of amylase activity, and the results are shown in table 3. 
Table 3: A multiple comparison and analysis on amylase activity

\begin{tabular}{cccc}
\hline Separation method & OD value & $\mathrm{X}-3$ & $\mathrm{X}-2$ \\
\hline Spore separation & 0.274 & $0.052^{* *}$ & $0.023^{*}$ \\
Sporocarp separation & 0.251 & $0.029^{*}$ & \\
$\begin{array}{c}\text { Mushroominhabiting wood } \\
\text { separation }\end{array}$ & 0.222 & & \\
& & &
\end{tabular}

Note: (1) The above statistics was about the results of randomly selecting 3 bottles in each repeated test; (2) enzyme activity was expressed with $O D$ value

The result in table 3 showed that extracellular enzyme (amylase) activities of the strains obtained using spore separation, sporocarp separation, and mushroominhabiting wood separation, in turn, ranked from strong to weak; amylase activity became the strongest when spore separation was applied; the strain obtained using spore separation was significantly stronger than those using mushroominhabiting wood separation and sporocarp separation.

\subsection{High-temperature resistance test results and analysis}

The strains, obtained using spore separation, sporocarp separation, and mushroominhabiting wood separation, were tested in terms of high-temperature resistance, and the results are shown in table 4.

Table 4: A multiple comparison on high-temperature resistance

(Unit: $\mathrm{cm} / \mathrm{d}$ )

\begin{tabular}{cccc}
\hline Separation method & $\begin{array}{c}\text { Culturing rate at } \\
\text { constant temperature }\end{array}$ & $\begin{array}{c}\text { Growing rate in } \\
\text { high-temperature } \\
\text { resistance test }\end{array}$ & Difference \\
\hline Spore separation & 0.39 & 0.38 & 0.01 \\
$\begin{array}{c}\text { Sporocarp separation } \\
\text { Mushroominhabiting }\end{array}$ & 0.37 & 0.37 & 0.00 \\
wood separation & 0.32 & 0.12 & $0.20^{* *}$
\end{tabular}

Note: (1) The above statistics was about the results of randomly selecting 3 bottles in each repeated test; (2) the degree of high-temperature resistance was expressed with difference

The test result in table 4 showed that the strains obtained using spore separation and sporocarp separation were resistant to high temperature, but the strain obtained using mushroominhabiting wood separation was not resistant to high temperature.

\section{Conclusion}

First, the mother strains of auricularia auricular, obtained using different separation methods, were different in the growing rate and condition on the above PDA synthetic medium; the mycelium growing rate, trend, and germination rate of the strain obtained using spore separation were better than those of the strain obtained using mushroominhabiting wood separation and 
slightly surpassed those of the strain obtained using sporocarp separation.

Second, it is known well that mother strains and mushroominhabiting wood are necessarily chosen in a cautious way if mother strains are separated using different methods, and unbroken and fresh sporocarp without diseases and normaly growing mushroominhabiting wood are better to be chosen. This study shows that separation methods are very important to consider if mother strains are necessarily obtained using separation methods, and auricularia auricular mother strains obtained using spore separation are better than those obtained using other methods and also their regeneration ability is more excellent.

In this experimental study, the quality of mushroom type, shape, and basswood, different separation methods, and culture medium types were considered, thus promoting the mother strains to grow fast and good. However, other properties are necessary to further study.

\section{Acknowledgement}

This paper aided financially by the Natural Foundation Research Project of the Science and Technology Department of Shaanxi Province (No.2014JM3078), agricultural brainstorm project of the Science and Technology Department of Shaanxi Province (No.2011K02-11), and the project of science and technology bureau of Yan'an (No.2012Ks-13).

\section{References}

[1] Deming CHEN, Jianchun HUANG. Edible Fungus Production Technical Manual [M]. Shanghai: Shanghai Science and Technology, 2001, P.228-229.

[2] Zhenyang LIU, Aihua TAN, Huide YANG, et al. Edible fungi cultivation $[\mathrm{M}]$. Wuhan: Central China Normal University Press, 2006, 124-125.

[3] He-xiang WANG, Ming LI, Cheng-jin GUO, et al. Edible fungi [M]. Beijing: China Agricultural University Press, 2004, p.102-103.

[4] Zhenyang LIU, Aihua TAN, Huide YANG, et al. Edible Fungi Cultivation [M]. Wuhan: Central China Normal University Press, 2006, p.01-02.

[5] Xinyi CHAI, Meiying WANG, Xuefeng XU, et al. The Development of Edible Fungi Industry in China and the Developing Strategies [J]. Journal of Resources Development and Market, 2006, 5(4): p.27-28.

[6] Shuang WANG. The Classification and Control of Microbiological Hazards in the Production of Edible Fungi [J]. Journal of Chongqing University (Natural Science Edition), 2007, 24 (1): 26-28. 